\title{
Modified Polypropylene Nonwoven Textile for Filter Facial Masks
}

\author{
Radka Kopecká*, Jiří Př́íhoda and Ladislav Pospíšil \\ Department of Chemistry, Masaryk University Brno, Czech Republic
}

*Corresponding author: Radka Kopecká, Department of Chemistry, Masaryk university, A12, Kamenice 5 625 00, Brno-Bohunice, Czech Republic.

To Cite This Article: Radka Kopecká. Modified Polypropylene Nonwoven Textile for Filter Facial Masks. 2020 - 9(5). AJBSR.MS.ID.001423. D0I: 10.34297/AJBSR.2020.09.001423.

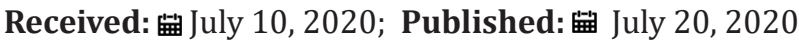

\section{Introduction}

Coronavirus (COVID-19) the most frequently spreads from human-to-human through respiratory droplets. Due to the outbreak of the COVID-19 pandemic in 2020, the research of protective equipment, especially facial masks, increased significantly. The filtering materials of facial masks are typically nonwoven textile. These materials, initially using natural fibers, came into greater importance with the introduction of synthetic thermoplastics, particularly polypropylene (PP), which creates the basic material for nonwoven textile for facial masks production. PP is non-toxic, hydrophobic material, resistant to steam sterilization, with a good ability to be fiberized. Unfortunately, it is also relatively sensitive to microbial attacks, such as bacteria, viruses, and mould [1,2]. Therefore, a less microbially sensitive chlorinated polypropylene derivative (CPP) was electrospun and tested for production of nonwoven masking fibers. CPP is also non-toxic, tasteless, hydrophobic, yellowish thermoplastic polymer with the higher resistance to oxidation and steam sterilization.

\section{Materials and Methods}

CPP granulates (Mw 100,000; $\mathrm{Tg}$ (DSC) $54{ }^{\circ} \mathrm{C}$; up to $26 \mathrm{wt} \%$ chlorine content) were dissolved in tetrahydrofuran (THF), so that the mass concentrations CPP was $10 \%$. THF was purified by distillation (b.p. $66^{\circ} \mathrm{C}$ ). Oxidative agents $\mathrm{H}_{2} \mathrm{O}_{2}$ and $\mathrm{HNO}_{3}$ were used in the commercial quality.

The electrospinning process was carried out using Elmarco Nanospider ${ }^{\mathrm{TM}}$ NSLAB 500 pilot plant unit, cylindrical electrode, rotation speed $10.2 \mathrm{rpm}$. The distance between electrodes was 120 $\mathrm{mm}$. The collecting foil was moving with the speed of $0.1 \mathrm{~m}$. min-1 [3] . The homogeneity of nonwoven textile and fibre structure were observed by SEM, using SEM Tescan MIRA3. The imaging used secondary emission mode, depth regime of $15 \mathrm{kV}$, working distance of $10 \mathrm{~mm}$ and a magnification of 20.000 times. The contrastenhancing colouring was used for contrast visualization. The average fibre width (FW) was calculated from manually marked 10 fibres width [4-6]. The surface hydrophobicity was determined by measuring water contact angle (CA), using a Digidrop contact angle measuring device (Surface Energy Evaluation System), from DataPhysics [7,8]. $1 \mu \mathrm{l}$ distilled water was placed on the sample surface, the water contact angle value was determined from the droplet image by tangent method, using software SCA 20. Sterilization treatment tests of CPP nonwoven textile was performed with $2 \times 3 \mathrm{~cm}$ long fibre samples, placed on glass slides, and fixed by an elastic band for.

\section{Experimental Results and Discussion}

Commercial PP fibres used for facing masks measure approximately about $25 \mu \mathrm{m}$ in diameter, whereas electrospun CPP nonwoven textile fibres reach only approximately $0.95 \mu \mathrm{m}$ in diameter. Due to this fact, the CPP filter facing mask material could be used in thinner layer with denser fiberization, with higher protective effect. SEM images confirm homogenous fibre structure with randomly fibre orientation. Water contact angle analysis determinate hydrophobic behavior (Figure 1). Presents the SEM images of fibre samples and data for CA measurements. Nonwoven samples were treated first by water steam, which can be also used for PP fibre facile mask material sterilization. Then CPP samples were submerged into $\mathrm{H}_{2} \mathrm{O}_{2}$ (concentration 35\%) and $\mathrm{HNO}_{3}$ (concentration 65\%) for $30 \mathrm{~min}$. Both treated fiber structures were subsequently compared with commonly used steam sterilized fiber structure. No morphological changes were observed. The CA values of treated fibers do not vary a lot, so hydrophobicity behavior was not significantly changed. 


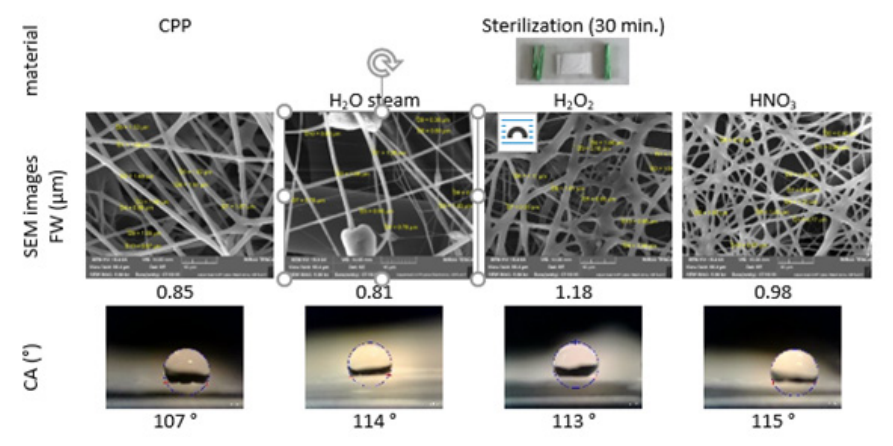

Figure 1: SEM nonwoven fiber structure, FW, CA.

\section{Conclusion}

Resistant CPP polymer was successfully fiberized using electrospinning technology. Fiberized CPP nonwoven textile seems to be an excellent filter material against viruses and other microorganisms. We concluded from this study that CPP fibres could greatly reduce viruses and bacterial penetration through the mask because of the textile morphology. In current medical masks, PP is compressed into several layers of membrane, the thinner CPP fibres could allow to use less layers due to their structure and higher fibre density. Moreover, the CPP capability to be repetitively sterilized by water steam as well as by an oxidizing agent make the material potentially interesting for commercial production. The experiments used in this study were simple but effective, presented the ability of CPP nonwoven textile formation using electrospinning technique, fibres exposing high homogeneity of fibre structure, hydrophobicity, and oxidative stability.

\section{Reference}

1. Mahdavi Fatemeh-Sadat, Armin Khavandegar,Parham Mardi (2020) Impact of SARS-CoV-2 On St-Elevation Myocardial Infarction (STEMI). American Journal of Biomedical Science \& Research 9(1): 73-75.

2. Huang JT, VJ Huang (2016) Evaluation of the Efficiency of Medical Masks and the Creation of New Medical Masks. Journal of International Medical Research 35(2): 213-223.

3. Doshi Jayesh, Darrell H Reneker (1995) Electrospinning process and applications of electrospun fibers. Journal of Electrostatics. 35(2-3): 151160 .

4. Mira ML Tescan (2016) Tescan Orsay Holding.

5. https://imagej.nih.gov/ij/

6. (2016) Software-Aztec 2.1G. Joa software and services. Dostupné z:

7. (2008) Advex Instruments. Advex Instruments, s. r. o.

8. (2013) Adhesives - Wettability - Determination by measurement of contact angle and surface free energy of solid surface. Praha: Úřad pro technickou normalizaci, metrologii a státní zkušebnictví. 